\title{
Effect of Temperature on the Growth of Mycoplasma gallisepticum and on Its Inhibition by Antiserum
}

\author{
By G. N. WOODE* \\ Department of Veterinary Pathology, Royal (Dick) School of \\ Veterinary Studies, Edinburgh \\ AND D. A. MCMARTIN \\ Ministry of Agriculture, Fisheries and Food, Veterinary Laboratory, \\ Eskgrove, Lasswade, Midlothian
}

(Received I5 March I973; revised 4 February 1974)

In the adult chicken, Mycoplasma gallisepticum does not extend readily beyond the nasal cavity, although lesions are caused even by small numbers of organisms following their inoculation directly into the abdominal air sacs (Grumbles, Boney \& Delaplane, 1952; Nelson, 1953; McMartin \& Adler, 1961). This may be explained by the difference in temperature of several degrees between the nasal cavity and abdominal air sacs, the latter being slightly below the body temperature of $40 \cdot 7^{\circ} \mathrm{C}$ (Herin, Booth \& Johnson, 1960), as Gill (1962) reported that growth was inhibited at $42{ }^{\circ} \mathrm{C}$. To investigate the influence of temperature on the organism, studies were made on the rate of growth, inhibition by antiserum and the role of heat labile components of normal serum on this inhibition, at incubation temperatures of 37 and $40.5^{\circ} \mathrm{C}$, using methods previously described (Woode \& McMartin, 1973).

The critical temperature for growth of $M$. gallisepticum was $4 \mathrm{I} \cdot 5^{\circ} \mathrm{C}$, determined on four separate occasions by incubating replicate cultures at $4 \mathrm{I}, 4 \mathrm{I} \cdot 5$ and $42{ }^{\circ} \mathrm{C}$. Growth occurred at $4 \mathrm{I}{ }^{\circ} \mathrm{C}$, at $4 \mathrm{I} \cdot 5{ }^{\circ} \mathrm{C}$ on two of four occasions, and was inhibited at $42{ }^{\circ} \mathrm{C}$.

The metabolic inhibition (m.i.) test was performed in tubes held in water baths at 37 and $40 \cdot 5^{\circ} \mathrm{C}$. Growth at $40 \cdot 5^{\circ} \mathrm{C}$ was delayed by $48 \mathrm{~h}$ as compared with cultures at $37^{\circ} \mathrm{C}$, but the early m.i. titre was the same at both temperatures. As the higher temperature had not influenced the inhibitory effect of high dilutions of antiserum, the effect on loss of viability by low dilution of antiserum was studied. Replicate cultures were incubated in $10 \%(\mathrm{v} / \mathrm{v})$ horse serum (HS) broth or $10 \%(\mathrm{v} / \mathrm{v})$ freshly prepared chicken serum (CS) broth, in the presence of a $\mathrm{I}: 20$ dilution of antiserum. Control HS broth cultures without antiserum were included (Fig. I $a$ ). Growth at $40.5^{\circ} \mathrm{C}$ was appreciably less than at $37^{\circ} \mathrm{C}$, and the rate of loss of viability by antiserum was greater with $\mathrm{CS}$ in the broth and at $40 \cdot 5^{\circ} \mathrm{C}$.

We did not determine whether lysis occurred during inactivation of the organism by low dilutions of antiserum, as at the concentration used visualization of the organism was not possible. However, lysis appears unlikely as the main mechanism of loss of viability when the length of time required for complete loss is considered. Taylor-Robinson \& Berry (1969) reported that heat labile components of guinea-pig serum had little effect on the m.i. test, but it is known that avian complement is required for the complement-associated antigenantibody reaction (Benson, Brumfield \& Pomeroy, 196I). The role of heat labile com-

\footnotetext{
* Present address: Institute for Research in Animal Diseases, Compton, nr Newbury, Berkshire RGI6 ONN.
} 


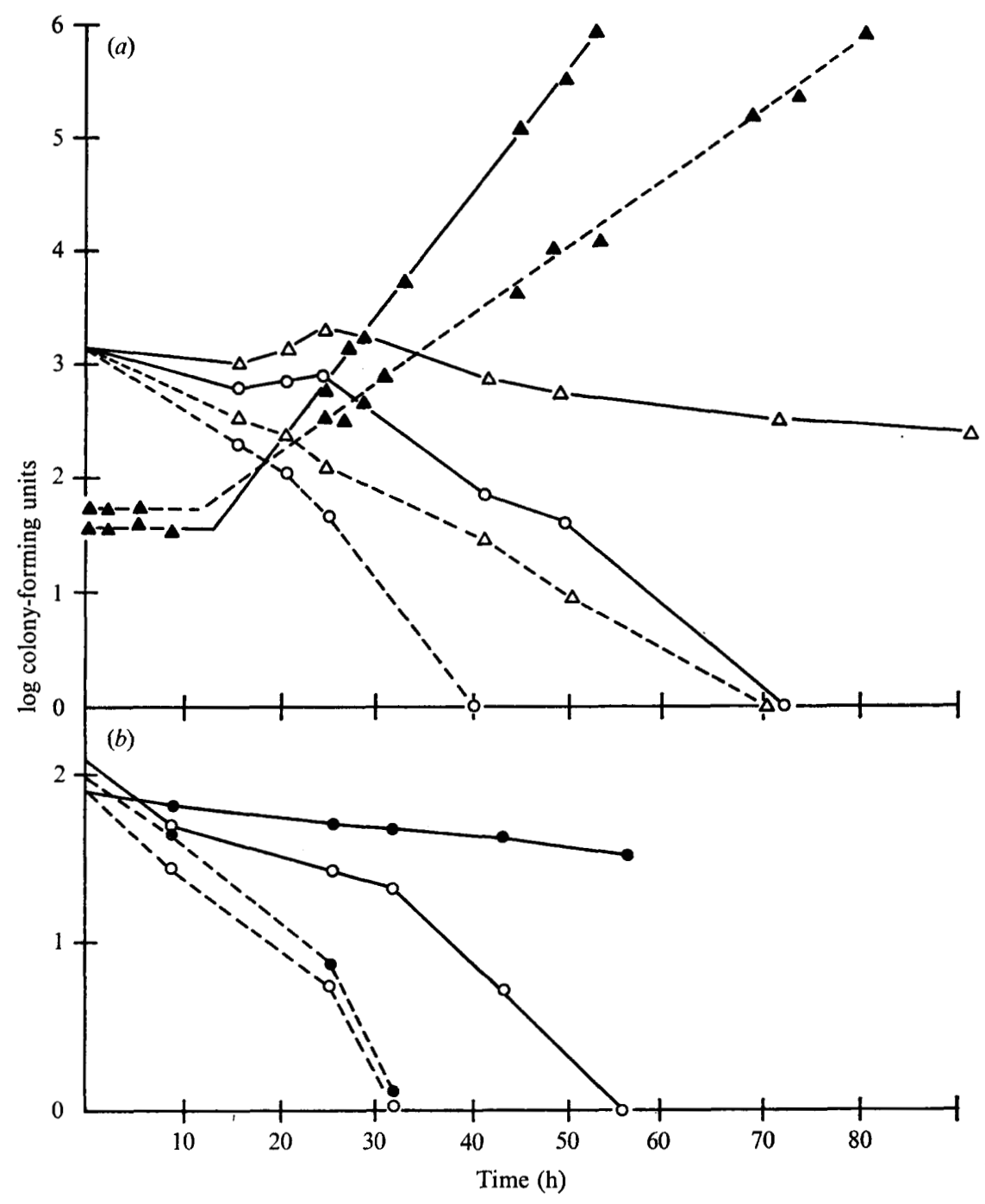

Fig. I. The effect of temperature on (a) growth and loss of viability of $M$. gallisepticum in antiserum with HS or CS in the broth, and $(b)$ on loss of viability in antiserum in the presence of heated or unheated $\mathrm{CS}$ in the broth. Incubation at $37^{\circ} \mathrm{C}$ (full line) or $40.5^{\circ} \mathrm{C}$ (broken line), with HS (A), HS and antiserum $(\triangle), C S$ and antiserum $(O)$ or heated $C S$ and antiserum $(\odot)$ present.

ponents was studied by performing the m.i. test in broth containing normal or heated $\left(56^{\circ} \mathrm{C}\right.$ for $\left.30 \mathrm{~min}\right) \mathrm{HS}$ and $\mathrm{CS}$. Heat treatment of HS did not influence the early or late $\mathrm{m}$.i. titre, nor did heating of the CS influence the early m.i. titre. However, late m.i. titres with CS broth were, on average, twofold lower after heat treatment. The rate of loss of viability of the organism in a $\mathrm{I}: 20$ dilution of antiserum in broth with heated CS was similarly reduced at $37{ }^{\circ} \mathrm{C}$, but was unaffected at $40 \cdot 5{ }^{\circ} \mathrm{C}$ (Fig. I $b$ ).

These results show that the effects of temperature and antiserum on the organism are complex. The rate of growth is reduced, the inhibitory effect of low dilutions of antiserum are enhanced, and the heat labile components only affect the rate of loss of viability at $37^{\circ} \mathrm{C}$. 
These observations support the suggestion by Davies (1969) that the bacteristatic and bactericidal activities of antiserum are dependent on a number of factors including the stage of antigenic stimulation and response to complement.

\section{REFERENCES}

Benson, H. N., Brumfield, H. P. \& Pomeroy, B. S. (1961). Requirement of avian C/1 for fixation of guinea pig complement by avian antibody-antigen complexes. Immunology 5, 616-622.

Davies, G. (1969). Observations of the growth-inhibiting properties of some antisera for Mycoplasma mycoides. Journal of Comparative Pathology 79, 293-299.

GILL, J. W. (1962). Culture and metabolism of Mycoplasma gallisepticum. Journal of Bacteriology 83, 213218.

Grumbles, L. C., Boney, W. A. \& Delaplane, J. P. (1952). The spread of infectious sinusitis of turkeys to chickens by natural means. Poultry Science 3r, 809-81 2.

Herin, R. A., Booth, N. H. \& Johnson, R. M. (1960). Thermo-regulatory effects of abdominal air sacs on spermatogenesis in domestic fowl. American Journal of Physiology 198, 1343-1345.

MCMARTIN, D. A. \& Adler, H. E. (196I). An immunological phenomenon in chickens following infection with Mycoplasma gallisepticum. Journal of Comparative Pathology and Therapeutics 71, 31 1-323.

Nelson, J. B. (1953). Micro-organisms of the Pleuropneumonia group and their relation to chronic respiratory disease. 25th Annual Meeting North East Conference Laboratory Workers in Pullorum Disease Control.

TAYloR-Robinson, D. \& BeRry, D. M. (1969). The evaluation of the metabolic inhibition technique for the study of Mycoplasma gallisepticum. Journal of General Microbiology 55, I27-1 37.

Woode, G. N. \& MCMARTIN, D. A. (1973). Metabolic and growth inhibition of Mycoplasma gallisepticum by antiserum. Journal of General Microbiology 75, 43-50. 